\title{
Ibuprofen is superior to paracetamol for pain relief following third molar removal
}

\author{
Abstracted from \\ Bailey E, Worthington HV, van Wijk A, Yates JM, Coulthard P, Afzal Z. \\ Ibuprofen and/or paracetamol (acetaminophen) for pain relief after surgical removal of lower wisdom teeth. \\ Cochrane Database Syst Rev 2013; 12: Art. No. CD004624. DOI: 10.1002/14651858.CD004624.pub2. \\ Address for correspondence: Luisa Fernandez Mauleffinch, Review Group Co-ordinator, \\ Cochrane Oral Health Group, School of Dentistry, The University of Manchester, Coupland III Building, \\ Oxford Road, Manchester, M13 9PL, UK. E-mail: luisa.fernandez@manchester.ac.uk
}

\section{Question: Following third molar removal which analgesic is most effective?}

Data sources The Cochrane Oral Health Group's Trials Register, the Cochrane Central Register of Controlled Trials (CENTRAL), Medline, Embase and the metaRegister of Controlled Trials were searched with no language restrictions.

Study selection Randomised controlled double-blinded clinical trials using the third molar model were included.

Data extraction and synthesis Two review authors independently and in duplicate extracted data. The proportion of patients with at least 50\% pain relief (based on total pain relief (TOTPAR) and summed pain intensity difference (SPID) data) was calculated for all three drugs at both two and six hours post-dosing and meta-analysed for comparison.

Results Seven studies involving 2241 patients were included. Two studies were considered to be at low risk of bias, three at high risk and two unclear risk of bias. Ibuprofen was found to be a superior analgesic to paracetamol at several doses, with high quality evidence suggesting that ibuprofen $400 \mathrm{mg}$ is superior to $1000 \mathrm{mg}$ paracetamol based on pain relief (estimated from TOTPAR data) and the use of rescue medication meta-analyses. Risk ratio (RR) for at least $50 \%$ pain relief (based on TOTPAR) at six hours was 1.47 (95\% confidence interval (Cl) 1.28 to 1.69 ; five trials) favouring $400 \mathrm{mg}$ ibuprofen over $1000 \mathrm{mg}$ paracetamol, RR for not using rescue medication (also favouring ibuprofen) was 1.50 (95\% Cl 1.25 to 1.79 ; four trials). For combined drug RR for at least $50 \%$ of the maximum pain relief over six hours of 1.77 (95\% Cl 1.32 to 2.39 ) (paracetamol $1000 \mathrm{mg}$ and ibuprofen $400 \mathrm{mg}$ ) (one trial; moderate quality evidence). RR not using rescue medication $1.60(95 \% \mathrm{Cl} 1.36$ to 1.88$)$ (two trials; moderate quality evidence). Adverse events were comparable between the treatment groups, but no formal analysis could be undertaken. Conclusions There is high quality evidence that ibuprofen is superior to paracetamol at doses of $200 \mathrm{mg}$ to $512 \mathrm{mg}$ and $600 \mathrm{mg}$ to 1000 $\mathrm{mg}$ respectively based on pain relief and use of rescue medication data collected at six hours postoperatively. The majority of this evidence (five

This paper is based on a Cochrane Review published in the Cochrane Library 2013, issue 12 (see www.thecochranelibrary.com for information). Cochrane Reviews are regularly updated as new evidence emerges and in response to feedback, and the Cochrane Library should be consulted for the most recent version of the review. out of six trials) compared ibuprofen $400 \mathrm{mg}$ with paracetamol 1000 $\mathrm{mg}$, these are the most frequently prescribed doses in clinical practice. The novel combination drug is showing encouraging results based on the outcomes from two trials when compared to the single drugs.

\section{Commentary}

Post-op pain is a concern following any surgical procedure for patients and health care providers. Third molar extractions are not an exception. There is concern for appropriate pain management in this setting. Pain after extraction of third molars is common and it can impact quality of life for patients for a few days or as long as a few weeks. Practitioners need to be aware of different means of managing pain caused by inflammation following surgical procedures. It is known that anti-inflammatory drugs are the most useful for treating this type of pain. Paracetamol or narcotics alone may not have the same effect.

The wide use of narcotics has been a topic for discussion. A recent survey/study, sent to a small group of oral surgeons in Canada and the US, reflects that narcotics are still prescribed (hydrocodone and codeine) after surgical procedures. A small percentage will prescribe NSAIDs only. ${ }^{1}$

There is a rising trend to decrease the amount of narcotics prescribed due to the undesirable side effects. This is why this is a clinically relevant topic as to assessing the use of non-narcotic analgesics. The review had a specific question which was to find the best strategy for pain relief following wisdom teeth extraction based on the nature of this surgical procedure. Pain relief was assessed at different intervals and doses of ibuprofen, paracetamol and combinations in one pill.

As a Cochrane review, it was conducted with an appropriate methodology, only English databases were searched, a thorough critical appraisal was performed. A grade of the evidence for each outcome was presented using GRADEprofiler, summarising the findings, quality of evidence and strength of the recommendations.

The authors' grading for the individual drugs was considered high quality, so further research is very unlikely to change the estimate of effect. This reassures the use of Ibuprofen $400 \mathrm{mg}$ as a lone drug, with minimal need for redosing at six hours post-op. The outcome for the combination of ibuprofen $400 \mathrm{mg} /$ paracetamol $1000 \mathrm{mg}$ was moderate quality indicating that further research is likely to have an important impact on the authors' confidence of the effect and may change the estimate. Overall the majority of adverse events were minor in nature (GI effects, headaches and dizziness). 
A previous Cochrane review published in 2013 from the Cochrane Pain-Palliative supportive care group assessed the efficacy and effects of a single dose of ibuprofen and paracetamol in combination. ${ }^{2}$ It concluded that a combination of these drugs delivered longer lasting analgesia with less of a need for additional dosing.

Clinically, the challenge is that the combination pill is not available in all countries. This may impact the patients' cooperation since they may not wish to take multiple pills.
Debra M Ferraiolo and Analia Veitz-Keenan

NYU College of Dentistry, New York, USA

1. Pynn BR, Laskin DM. Comparison of Narcotic Prescribing Habits and Other Methods of Pain Control by Oral and Maxillofacial Surgeons in the United States and Canada. J Oral Maxillofac Surg 2014; pii: S0278-2391(14)01072-6. doi: 10.1016/j. joms.2014.06.436. [Epub ahead of print]

2. Derry C], Derry S, Moore RA. Single dose oral ibuprofen plus paracetamol (acetaminophen) for acute postoperative pain. Cochrane Database Syst Rev. 2013; 6: CD010210. doi: 10.1002/14651858.CD010210.pub2.

Evidence-Based Dentistry (2014) 15, 106-107. doi:10.1038/sj.ebd.6401059 